\title{
Acoustic Wave Dispersion and Scattering in Complex Marine Sediment Structures
}

\author{
Charles W. Holland \\ The Pennsylvania State University \\ Applied Research Laboratory \\ P.O. Box 30 \\ State College, PA 16804-0030 \\ Phone: (814) 865-1724 Fax (814)863-8783 email: holland-cw@psu.edu
}

Grant Number: N00014-14-1-0224

\section{LONG TERM GOALS}

The long term science goals are to understand and quantify the physical mechanisms that control propagation and scattering in the seabed.

\section{OBJECTIVES}

The objectives are to advance understanding of 1) the nature and mechanisms leading to sediment volume scattering and 2) the effects of shear waves in general layered media. These advances will provide the basis for measuring dispersion in in-situ sediments in the frequency range of interest, 0.1 $10 \mathrm{kHz}$.

\section{APPROACH}

The project commenced in FY14 with advances in modeling for both shear waves and volume scattering.

\section{WORK COMPLETED}

A brief summary of the work completed is listed below:

- Improvement of Viscous Grain Shearing (VGS) model [1] in collaboration with Mike Buckingham. We show that the shear time constant is completely and rigorously defined by the other parameters (i.e. is not a parameter itself), see Ref. [2].

- Initial theoretical development of sediment volume scattering relationships between discrete vs continuum points of view. This work is in its early stages.

\section{RESULTS}

The Viscous Grain Shearing model developed by Mike Buckingham [1] predicts the frequency dependence of compressional and wave speeds and attenuations. The bonding/loss mechanisms are 


\section{Report Documentation Page}

Form Approved

OMB No. 0704-0188

Public reporting burden for the collection of information is estimated to average 1 hour per response, including the time for reviewing instructions, searching existing data sources, gathering and maintaining the data needed, and completing and reviewing the collection of information. Send comments regarding this burden estimate or any other aspect of this collection of information,

including suggestions for reducing this burden, to Washington Headquarters Services, Directorate for Information Operations and Reports, 1215 Jefferson Davis Highway, Suite 1204, Arlington

VA 22202-4302. Respondents should be aware that notwithstanding any other provision of law, no person shall be subject to a penalty for failing to comply with a collection of information if it

does not display a currently valid OMB control number.

\begin{tabular}{|c|c|c|}
\hline $\begin{array}{l}\text { 1. REPORT DATE } \\
\mathbf{3 0} \text { SEP } \mathbf{2 0 1 4}\end{array}$ & 2. REPORT TYPE & $\begin{array}{l}\text { 3. DATES COVERED } \\
\mathbf{0 0 - 0 0 - 2 0 1 4} \text { to 00-00-2014 }\end{array}$ \\
\hline \multirow{3}{*}{\multicolumn{2}{|c|}{$\begin{array}{l}\text { Acoustic Wave Dispersion and Scattering in Complex Marine Sediment } \\
\text { Structures }\end{array}$}} & 5a. CONTRACT NUMBER \\
\hline & & 5b. GRANT NUMBER \\
\hline & & 5c. PROGRAM ELEMENT NUMBER \\
\hline \multirow{3}{*}{\multicolumn{2}{|c|}{ 6. AUTHOR(S) }} & 5d. PROJECT NUMBER \\
\hline & & 5e. TASK NUMBER \\
\hline & & 5f. WORK UNIT NUMBER \\
\hline \multicolumn{2}{|c|}{$\begin{array}{l}\text { 7. PERFORMING ORGANIZATION NAME(S) AND ADDRESS(ES) } \\
\text { Pennsylvania State University,Applied Research Laboratory,PO Box } \\
\text { 30,State College,PA,16804 }\end{array}$} & $\begin{array}{l}\text { 8. PERFORMING ORGANIZATION } \\
\text { REPORT NUMBER }\end{array}$ \\
\hline \multirow{2}{*}{\multicolumn{2}{|c|}{ 9. SPONSORING/MONITORING AGENCY NAME(S) AND ADDRESS(ES) }} & 10. SPONSOR/MONITOR'S ACRONYM(S) \\
\hline & & $\begin{array}{l}\text { 11. SPONSOR/MONITOR'S REPORT } \\
\text { NUMBER(S) }\end{array}$ \\
\hline
\end{tabular}

12. DISTRIBUTION/AVAILABILITY STATEMENT

Approved for public release; distribution unlimited

13. SUPPLEMENTARY NOTES

14. ABSTRACT

15. SUBJECT TERMS

16. SECURITY CLASSIFICATION OF:

\begin{tabular}{c|c|c}
$\begin{array}{c}\text { a. REPORT } \\
\text { unclassified }\end{array}$ & $\begin{array}{c}\text { b. ABSTRACT } \\
\text { unclassified }\end{array}$ & $\begin{array}{c}\text { c. THIS PAGE } \\
\text { unclassified }\end{array}$
\end{tabular}

17. LIMITATION OF ABSTRACT

Same as

Report (SAR)
18. NUMBER 19a. NAME OF

OF PAGES RESPONSIBLE PERSON

3 
assumed to be shearing at the grain-to-grain contacts and fluid flow around the contacts. However, given that the physics of the frictional and viscous forces are not fully understood, the model uses simple material response functions with empirical parameters to model the gross or average system behavior. One of the strengths of the model is that it provides generalized dispersion relations that include both viscous and frictional losses. For compressional waves, the losses are described via a compressional viscoelastic time constant. There is also a shear viscoelastic time constant and our work (the PI in collaboration with Mike Buckingham) showed that there is an exact closed-form solution for this constant in terms of other model parameters. This will improve modeling of the frequency dependence of shear wave speed and attenuation in marine sediments (see Ref [2]).

\section{IMPACT/APPLICATIONS}

The VGS model advancement leads to an improved prediction capability for shear wave attenuation. The VGS theory is used in a variety of applications as a forward model, i.e., predicting the acoustic field resulting from reflection and transmission through marine sediments. It is also used as an inverse model, i.e., estimating sediment properties from acoustic wave reflection, transmission, and scattering. This theory will be used by several researchers to aid in planning for the upcoming ONR SCAE'16 field experiment in the north Atlantic, and subsequently for the data analysis.

In the long term, the theoretical relationships developed for volume scattering will improve our understanding of the marine benthic environment: what kind of scatterers are important, are they best described by a discrete or a continuum approach? In the shorter term, the results are important for reexamining recent volume scattering analyses [3] in several continental shelf environments. While the analysis in [3] assumed that the heterogeneities were described by a continuum with an outer scale of $0.1 \mathrm{~m}$, the current research will link those results to a discrete scatterer hypothesis. The importance of this is that the outer scale controls the frequency dependence of scattering and reverberation of active sonar systems. Furthermore, understanding the geologic origins of the outer scale could lead to a greater prediction capability for those systems.

\section{RELATED PROJECTS}

ONR shallow water field experiments, e.g., SCAE16: the advances here will motivate experiment design to distentangle effects of sediment dispersion from other frequency dependent effects.

OAML Mid-frequency Bottom Scattering Database. A prototype database was developed under sponsorship of PMW-120 (Marcus Speckhahn) drawing heavily on decades of 6.1 fundamental research on bottom scattering and reverberation. This database will replace the current default, Lambert's Law in one area of operational interest. While the database is moving towards OAML approval and subsequent extension to other regions of interest, there are several 6.1 questions about the nature of the scattering mechanism that are important to answer, particularly for the question of spatial extrapolation. Some of the questions addressed in the above proposal have direct relevance to database provincing and parameter extrapolation.

\section{REFERENCES}

[1] Buckingham M.J., On pore-fluid viscosity and the wave properties of saturated granular materials including marine sediments, J. Acoust. Soc. Am. 122, 1486, 2007. 
[2] Buckingham, M.J. and C.W. Holland, Determining the shear time constant in the Viscous Grain Shearing (lambda) Theory, VGS( $\lambda$ ),J. Acoust. Soc. Am., in review, 2014

[3] Holland C.W., Evidence for a common scale $\mathrm{O}(0.1) \mathrm{m}$ that controls seabed scattering and reverberation in shallow water, J. Acoust. Soc. Am., 132, 2232-2238, 2012.

\section{PUBLICATIONS}

Buckingham, M.S. and C.W. Holland, Determining the shear time constant in the Viscous Grain Shearing (lambda) Theory, $\operatorname{VGS}(\lambda)$,J. Acoust. Soc. Am., in review, 2014. 